\title{
An Experimental Test to Compare Viability of Various Theories of Atmospheric Velocity Fluctuations
}

Edmond M. Dewan

25 June 2001

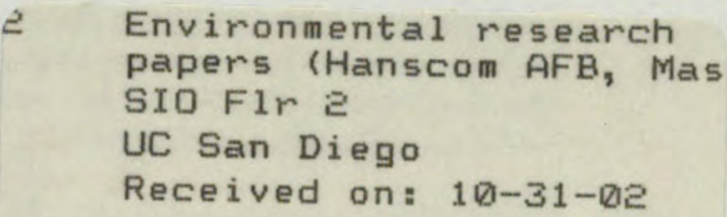

Approved for Public Release; Distribution Unlimited

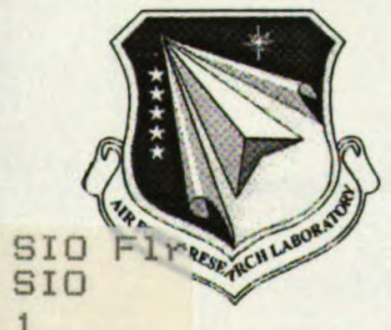

AIR FORCE RESEARCH LABORATORY Space Vehicles Directorate 29 Randolph Rd AIR FORCE MATERIEL COMMAND Hanscom AFB, MA 01731-3010

1

EN744

v. 1241 